NASA/TP-1998-207427

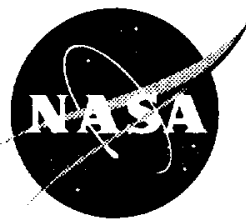

Design Considerations for Lightweight Space Radiators Based on Fabrication and Test Experience With a Carbon-Carbon Composite Prototype Heat Pipe

Albert J. Juhasz

Lewis Research Center, Cleveland, Ohio

National Aeronautics and

Space Administration

Lewis Research Center 


\section{Acknowledgments}

This work was carried out in support of the Civilian Space Technology Initiative (CSTI) at the NASA Lewis Research Center and its contractors, principally the Rocketd yne Division of the Rockwell International

(RI) Co., presently the Boeing Co. Hardware fabrication and experimental work was performed by RI under contract NAS 3-25209.

Available from

NASA Center for Aerospace Information 800 Elkridge Landing Road Linthicum Heights, MD 21090-2934

Price Code: A03
National Technical Information Service 5287 Port Royal Road Springfield, VA 22100 Price Code: A03 


\title{
Design Considerations for Lightweight Space Radiators Based on Fabrication and Test Experience With a Carbon-Carbon Composite Prototype Heat Pipe
}

\author{
Albert J. Juhasz. \\ National Aeronautics and Space Administration \\ Lewis Research Center \\ Cleveland, Ohio 44135
}

\section{Summary}

This report discusses the design implications for spacecraft radiators made possible by the successful fabrication and proof-of-concept testing of a graphite-fiber-carbon-matrix composite (i.e., carbon-carbon $(\mathrm{C}-\mathrm{C})$ ) heat pipe. The prototype heat pipe, or space radiator element, consists of a $\mathrm{C}-\mathrm{C}$ composite shell with integrally woven fins. It has a thin-walled furnacebrazed metallic ( $\mathrm{Nb}-1 \% \mathrm{Zr}$ ) liner with end caps for containment of the potassium working tluid. A short extension of this liner, at increased wall thickness beyond the C-C shell, forms the heat pipe evaporator section which is in thermal contact with the radiator fluid that needs to be cooled. During the fabrication process the $\mathrm{C}-\mathrm{C}$ shell condenser section was exposed to an atomic oxygen $(\mathrm{AO})$ ion source for a total $\mathrm{AO}$ fluence of $4 \times 10^{20}$ atoms $/ \mathrm{cm}^{2}$, thereby raising its surface emissivity for heat radiation to a value of 0.85 to 0.90 at design operating temperatures of 700 to $800 \mathrm{~K}$. The prototype heat pipe was extensively tested from startup at ambient conditions, with the working fluid initially in the frozen state, to a condenser temperature of nearly $700 \mathrm{~K}$. Post-test inspection showed the heat pipe to be in excellent condition after several thermal cycles from ambient to operating temperature.

The report also discusses the advantage of segmented space radiator designs utilizing heat pipe elements, or segments, in their survivability to micrometeoroid damage. This survivability is further raised by the use of condenser sections with attached fins, which also improve the radiation heat transfer rate. Since the problem of heat radiation from a fin does not lend itself to a closed analytical solution, a derivation of the governing differential equation and boundary conditions is given in appendix $\mathrm{A}$, along with solutions for rectangular and parabolic fin profile geometries obtained by use of a finite difference computer code written by the author.

From geometric and thermal transport properties of the $\mathrm{C}-\mathrm{C}$ composite heat pipe tested, a specific radiator mass of $1.45 \mathrm{~kg}$ / $\mathrm{m}^{2}$ can be derived. This is less than one-fourth the specific mass of present day satellite radiators. Using composites with ultrahigh conductivity would further reduce the area density of spacecraft radiators, and utilizing alternate heat pipe fluids with compatible liner materials would extend the $\mathrm{C}-\mathrm{C}$ heat pipe technology to a wide range of temperatures and applications.

\section{Introduction}

By virtue of the inherent parallel redundancy that they bring to space heat rejection subsystems, heat pipes are logical elemental building blocks for the construction of spacecraft radiators. In pumped loop space radiators, a micrometeoroid puncture of a cooling-fluid carrying tube would cause eventual loss of cooling fluid and, hence, failure of the radiator. In contrast, space radiators composed of a large number of heat pipes would be relatively immune to puncture from micrometeoroids or small space debris because loss of an individual heat pipe, whose function is completely independent of that of its neighbors, would result only in the loss of that small fraction of total radiating area represented by the punctured heat pipe's radiating surface. Thus, overall radiator reliability can be significantly enhanced, even with lower wall thickness of its heat pipe elements, which also would reduce radiator mass. Increased survivability coupled with reduced mass is of strategic importance in spacecraft power system radiators, since past studies of power systems with either solar or nuclear heat sources have shown (e.g., Brandhorst, Juhasz, and Jones. 1986; and Juhasz and Jones, 1986) that radiator weight accounts for a significant portion of overall spacecraft launch mass. Thus, application of graphite-carbon composite technology to space radiator heat pipes will lead to even greater savings in the total Earth-to-orbit mass that needs to be launched for a given mission, and thereby contribute to the "low-cost access to space" initiative, which is to be implemented during the early decades of the next century.

This report reviews and expands on the results of space radiator research conducted by the NASA Lewis Research Center and its contractors under the Civil Space Technology Initiative, as previously summarized by Juhasz and Peterson (1994) and Juhasz and Rovang (1995). The approach taken in extrapolating prototype $\mathrm{C}-\mathrm{C}$ heat pipe test results to the design of full-scale space radiators is analogous to that taken by Groll in proposing the use of heat pipes as elemental units, or building blocks, for various thermal applications in industry (Groll, 1973). Such an extrapolation is especially appropriate, because the development of very high conductivity composites that have the required mechanical and optical properties for space radiator use makes possible some highly attractive design options. 
Of these, the most impressive is one offering a radiator whose specific mass is more than fourfold less than that of a pumped loop design $\left(<1.5 \mathrm{~kg} / \mathrm{m}^{2}\right.$ compared to $6 \mathrm{to} 7 \mathrm{~kg} / \mathrm{m}^{2}$ ). At the same time it provides significantly higher survivability to micrometeoroid damage, owing to the redundancy of heat pipes.

Space limitations prevent an in-depth discussion of all aspects of the $\mathrm{C}-\mathrm{C}$ heat pipe design, fabrication, and testing carried out under a joint program between NASA Lewis and the Rockwell International Division of the Boeing Co.; however. this paper addresses the highlights and briefly analyzes radiating fin heat transfer, which is an essential feature of the proposed "integral fin" C-C heat pipe concept. Also included is a discussion of several potential radiator designs, based on the C-C heat pipe as an elemental unit of typical radiator panels, for space power systems ranging from multikilowatt to megawatt levels for space and lunar base applications.

\section{Discussion}

\section{Integral Fin $\mathrm{C}-\mathrm{C}$ Concept}

If a heat pipe were a single element or building block of a spacecraft radiator consisting of a large number of similar devices, obviously, any measures taken to increase the reliability and survivability of each of these elemental units in the space environment would reduce the vulnerability of the entire radiator to micrometeoroid damage. One such measure is the addition of fins over the heat pipe condenser section, a provision that can easily be accomplished during the weaving of the $\mathrm{C}-\mathrm{C}$ preform by using what is referred to as the integrally woven fin technique. To maximize radiation heat transfer at heat pipe operating conditions, the $\mathrm{C}-\mathrm{C}$ shell condenser section. including the radiating fins, was exposed to an atomic oxygen $(\mathrm{AO})$ ion source as part of the fabrication process. A total AO fluence of $4 \times 10^{20}$ atoms $/ \mathrm{cm}^{2}$ raised the surface emissivity for heat radiation to a value of 0.85 to 0.90 at design operating temperatures of 700 to $800 \mathrm{~K}$ (Rutledge et al., 1989).

For a detailed analysis of heat transfer from a radiating fin. including derivation of the governing second-order, fourthdegree ordinary differential equation (ODE), see appendix $\mathrm{A}$. The computer-coded numerical solution technique for this ODE was determined as part of this study. This technique permits generation of solutions not only for constant material properties (i.e.. thermal conductivity or surface emissivity) and rectangular fin profiles, but also for cases in which these properties are functions of temperalure and in which the fin profile (i.e.. the cross-sectional area normal to heat flow) varies with distance from the fin root along the main heat flow axis. Moreover, the option of heat transfer by combined radiation and convection can be readily implemented.

In addition to fins increasing the radiating surface area of the heat pipe condenser section. they are also impervious to damage from small particle impact since a punctured fin would not adversely affect the continued operation of the heat pipe. The ratio of the "vulnerable area of the heat pipe's working fluid containment portion" to "the overall heat pipe-plus-fin area" will thus decrease in inverse proportion to the fin width (which is defined as the linear dimension from the fin root to the fin (ip). In addition to increasing the survivability, and thus the reliability, of individual heat pipe radiator elements, fins would also reduce the radiator's specific mass. Of course, increasing the fin width while keeping constant the fin thickness and fin efficiency (total heat transferred by the fin divided by the total heat transferred if the entire fin were at the fin root temperature) would be a design option only if the thermal conductivity of the fin in the root-to-tip direction could also be increased by using a higher conductivity material.

This is illustrated in table I (with its accompanying dimensional sketch), which gives a breakdown of the integrated fin heat pipe component weights and surface areas for three $C-C$ composite materials of increasing thermal conductivity: $\mathrm{T}-\mathbf{3 0 0}$, P95WG, and K-1100, the highest thermal conductivity composite available when this work was conducted. However, with the rapid pace of $\mathrm{C}-\mathrm{C}$ composite material development, frequent product improvements can be expected. An example is a new thermal pyrolytic graphite material that has been developed for encapsulation within a metallic structural shell; this material's thermal conductivity values range from 1200 to $1700 \mathrm{~W} / \mathrm{m} \mathrm{K}$ (Montesano, 1996). A comparison of the specific mass valies in table I shows that increasing the thermal conductivity of a heat pipe material leads to significant reductions in heat pipe specific mass. The T-300 heat pipe, whose values are shown in the first column, was built and tested (see fig. 1(drawing) of prototype). Its specific mass of $2.1 \mathrm{~kg} / \mathrm{m}^{2}$ for two-sided heat rejection is a reduction of more than threefold over the specific mass of first-generation space station radiators. The heat pipe specified by the values in the second column (P-95 WG) was also fabricated. but it has not yet been tested because of funding limitations. A heat pipe with the values specifiec in the third column (K1100) could be fabricated with emerging very high conductivity materials. Here, specific mass values are approaching $1 \mathrm{~kg} / \mathrm{m}^{2}$.

\section{Heat Pipe Design and Fabrication Details}

To mot the radiator operating requirements for the SP- 100 power s: stem (nuclear reactor heat source coupled with thermoelect ic energy conversion), a heat pipe evaporator temperature of $875 \mathrm{~K}$ was required. Since at this temperature the heat pipe's potassium working fluid undergoes an intercalation reaction with the $\mathrm{C}-\mathrm{C}$ material, a barrier was needed between the inner surface of the $\mathrm{C}-\mathrm{C}$ tube and the potassium working fluid. Thus, a thin-walled metallic liner produced by Pacific Northwest Laboratories (PNL) of Richland. Washington, was used for this purpose. PNL produced this $\mathrm{Nb}-1 \mathrm{Zr}$ (niobium- $1 \%$ zirconium alloy) tubular liner by using a tube roller extrusion 
TABLE I.CARBON-CARBON HEAT-PIPE MASS BREAKDOWN FOR THREE COMPOSITES

\begin{tabular}{|l|c|c|c|}
\hline \multicolumn{1}{|c|}{ Material } & T300 & P95 WG & $\mathrm{K} 1100$ \\
\hline Thermal conductivity, W/mK & $50-80$ & $300-500$ & $750-1000$ \\
\hline Heat pipe dimensions, cm & & & \\
Length, L & 91.4 & 91.4 & 91.4 \\
Shell diameter, D & 2.5 & 2.5 & 2.5 \\
Width, W & 5 & 7.5 \\
Thickness, T & 0.1 & 0.1 & 0.1 \\
Heat pipe components mass, g & 169.5 & 214.0 & 254.5 \\
C-C shell & 41.2 & 41.2 & 41.2 \\
Liner with evaporator & 13.1 & 13.1 & 13.1 \\
End caps & 7.2 & 7.2 & 7.2 \\
Fill tubes & 22.5 & 22.5 & 22.5 \\
Braze & 24.0 & 24.0 & 24.0 \\
Foil wick & 13.5 & 13.5 & 13.5 \\
Working fluid & 291.0 & 335.5 & 376.0 \\
Total mass, g & 0.0691 & 0.116 & 0.16 \\
One-sided radiating area, $\mathrm{m}^{2}$ & 4.21 & 2.89 & 2.35 \\
Specific mass, $\mathrm{kg} / \mathrm{m}^{2}$ & & & \\
Two-sided radiating area, $\mathrm{m}^{2}$ & 0.1382 & 0.232 & 0.32 \\
Specific mass, $\mathrm{kg} / \mathrm{m}^{2}$ & 2.11 & 1.45 & 1.18 \\
\hline
\end{tabular}
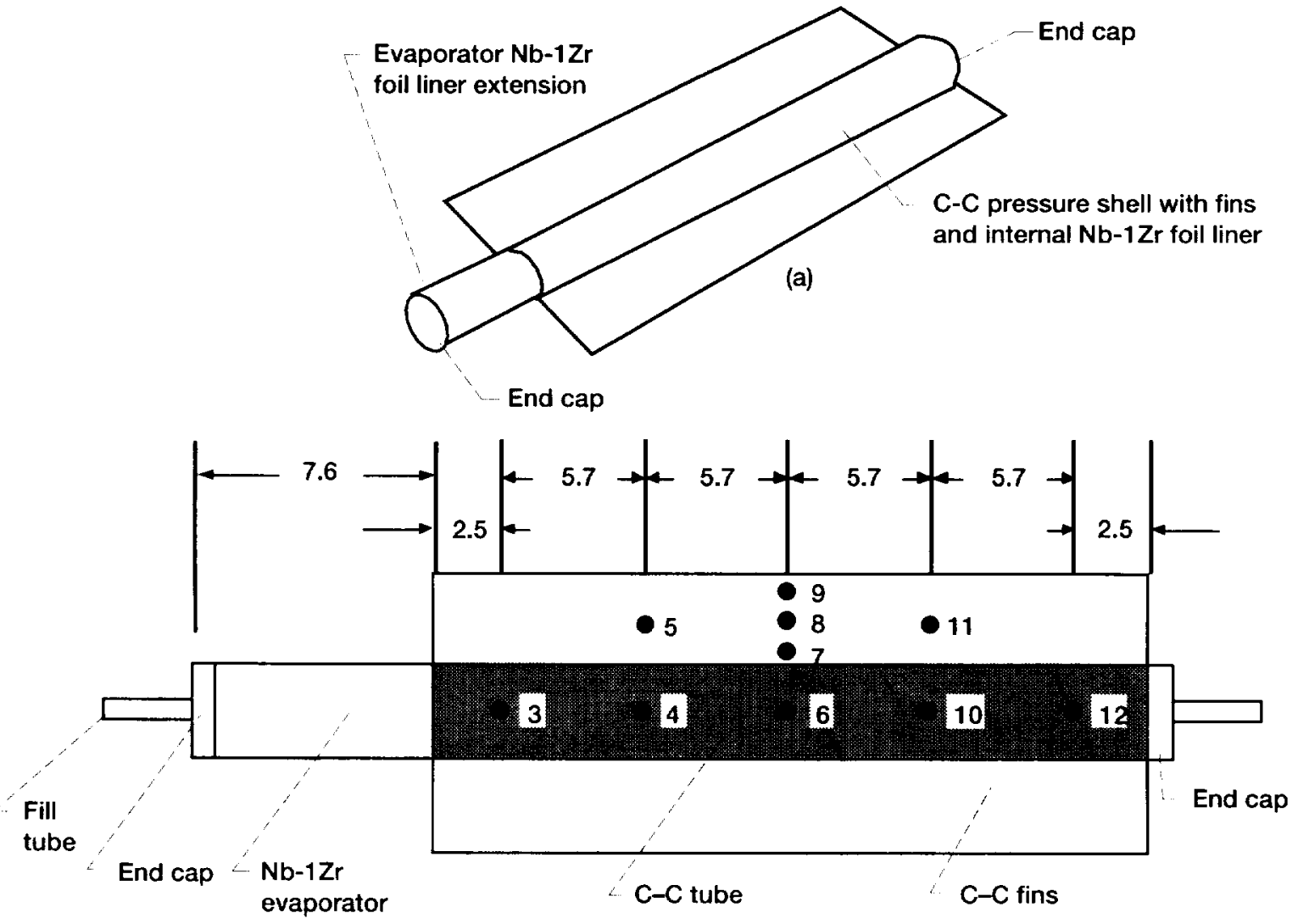

(b)

Figure 1.-Carbon-carbon heat pipe radiator element (all dimensions are in centimeters). (a) $C-C$ shell and metallic liner/evaporator extension. (b) Top view of test article showing thermocouple locations. 


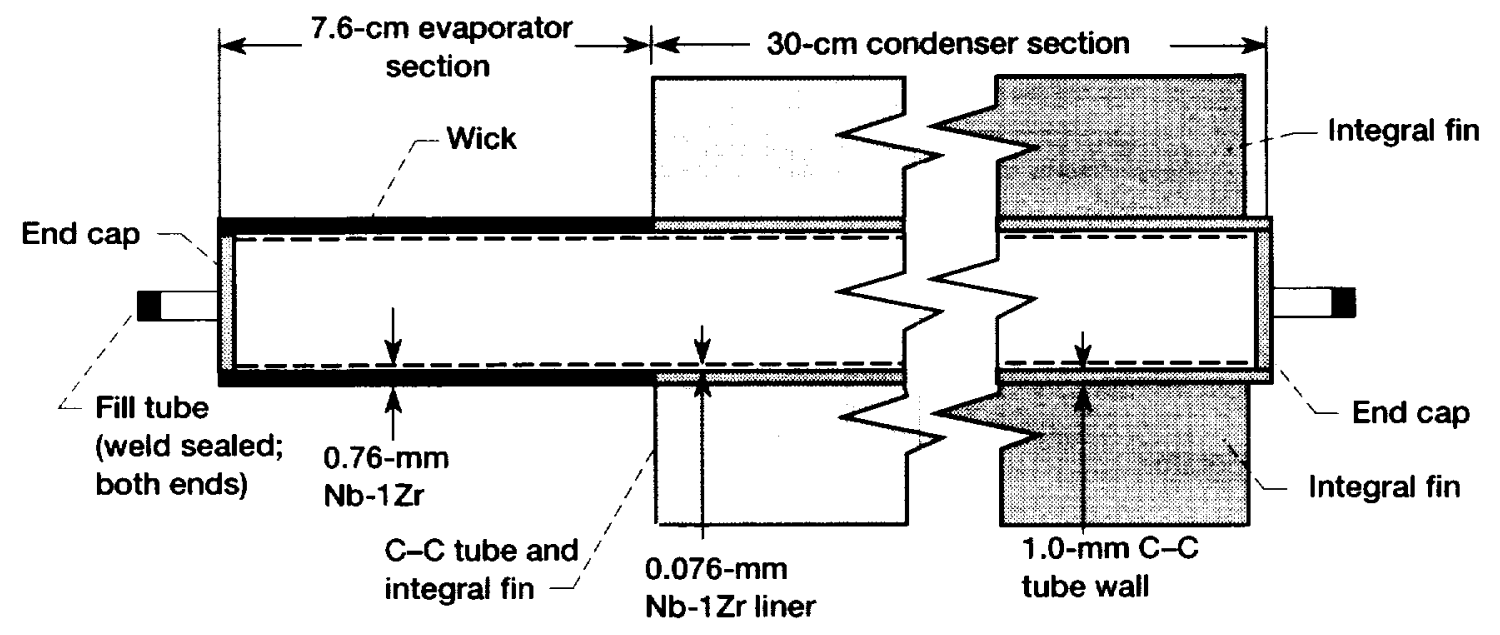

Figure 2.-Carbon-carbon test heat pipe design details.

process referred to as the "Uniscan." The liner had a 0.076-mmthick wall with a thicker wall $(0.76-\mathrm{mm})$ extension for the heat pipe evaporator. While pressurized with argon gas, the liner was furnace-brazed into the $\mathrm{C}-\mathrm{C}$ shell, as shown in the section view of figure 2 . Prior to the furnace-brazing operation, a wick was attached to the inner surface of the liner, and the end caps were welded to bothends, an especially significant accomplishment for the liner section that was only $0.076 \mathrm{~mm}$ thick. Fill tubes cut from $0.63-\mathrm{cm}$-diameter $\mathrm{Nh}-1 \mathrm{Zr}$ tubing were inserted into central holes in the end caps and welded in place. As mentioned previously, the heat pipe evaporator section was formed by the $7.6-\mathrm{cm}$ extension of the liner and had a wall thickness of $0.76 \mathrm{~mm}$.

\section{Wick Design and Fabrication}

Additional design details, including the positioning of the perforated molybdenum foil wick, are shown in figure 3 . The wick (fig. 4) was fabricated by using perforated molybdenum foil procured from the Buckbee Mears Co. of St. Paul, Minnesota. The foil was $0.038 \mathrm{~mm}$ thick and had evenly spaced 0.06-mm-diameter, sharp-edged perforations, as shown in the photomicrographs of figure 4(a) (magnified 50 times) and figure 4(b) (magnified 500 times). Although calculations showed that a niobium screen wick would provide capillary pumping even in a minus-one-g field, cost and scheduling constraints dictated the use of the perforated Mo wick. Computational analysis showed that this wick would provide capillary pumping at a $-11^{\circ}$ tilt angle; hence it was judged to meet the requirements for space service under microgravity conditions.

\section{Heat Pipe Assembly and Filling}

The actual components used in the assembly of the $\mathrm{C}-\mathrm{C}$ composite heat pipe are shown in figure 5. As previously mentioned, end caps with central fill tubes were first precision welded $t$ ) both ends of the liner. The liner itself was then furnace-trazed into the $\mathrm{C}-\mathrm{C}$ shell under inert gas (argon) pressure. To carry out this brazing process, silver ABA (ternary alloy) braze foil was wrapped around the pressurized, thinwalled cylinder and the package was inserted into the inner diameter of the $\mathrm{C}-\mathrm{C}$ tube, which was then placed into the furnace. The furnace brazing operation was carried out at nearly $100 \mathrm{~K}$-more than $200 \mathrm{~K}$ above the maximum heat pipe service temperature.

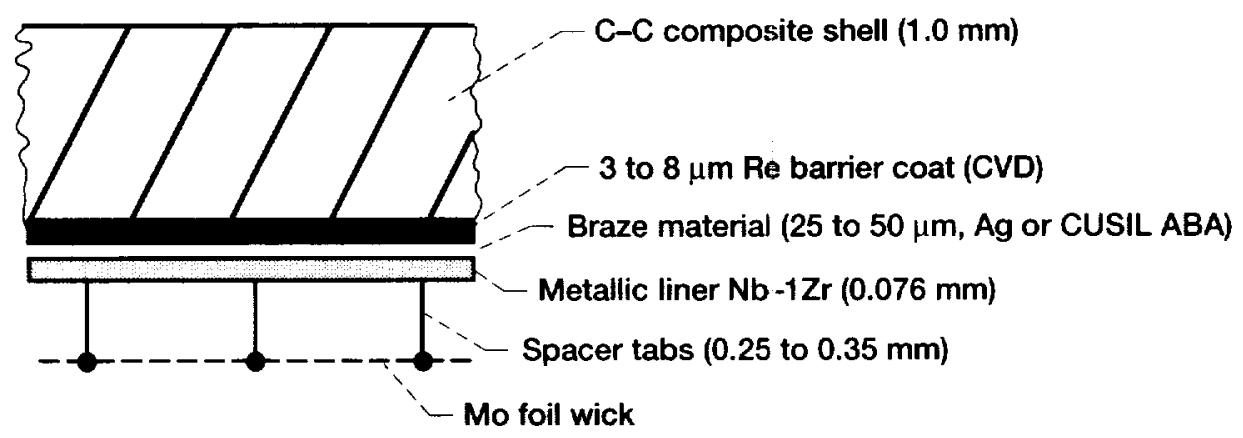

Figure 3.-Carbon-carbon shell and metal foil liner braze details. 

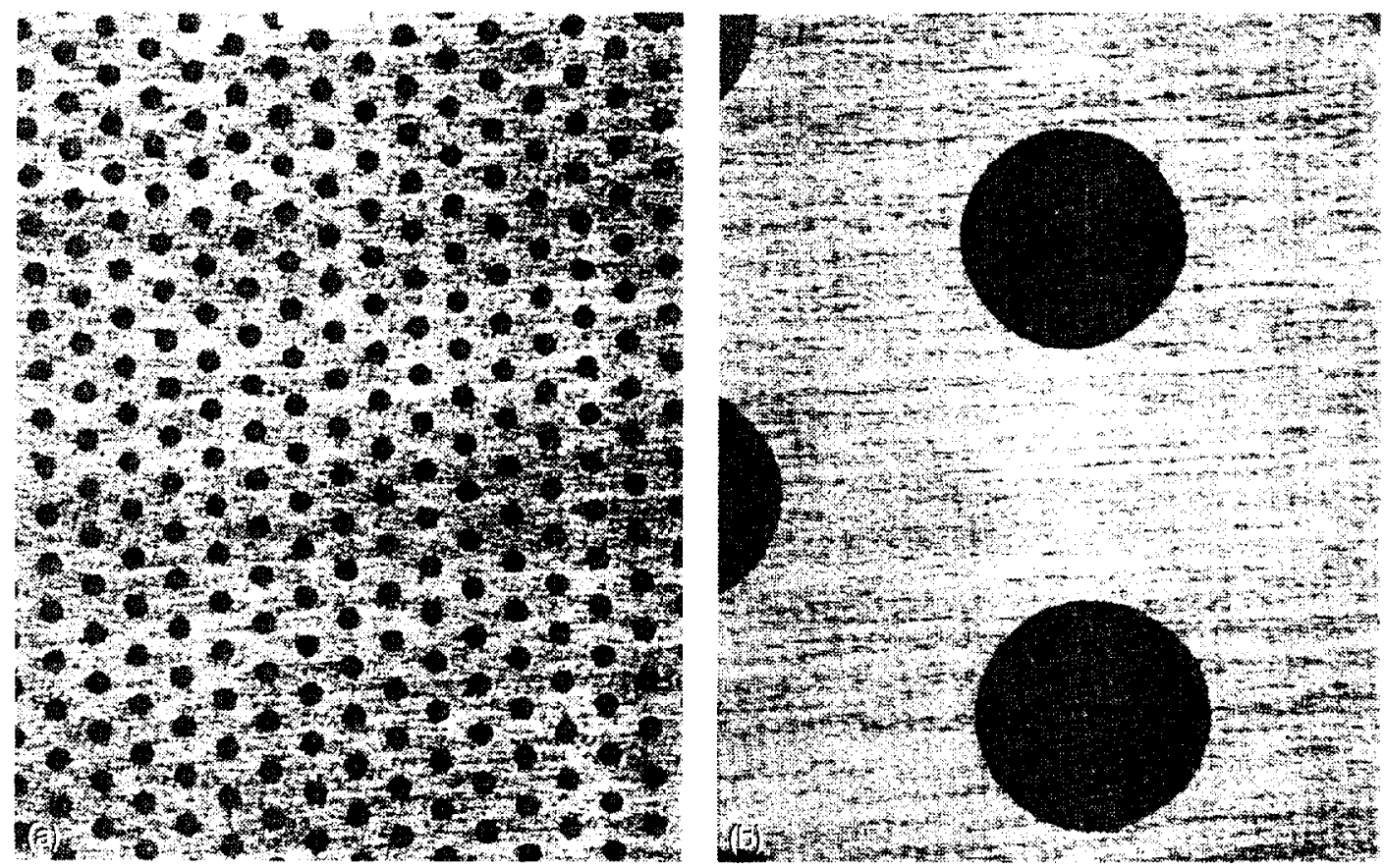

Figure 4.-Molybdenum foil wick photomicrographs showing spacing uniformity of sharp-edged 0.06-mm-diameter holes. (a) At magnification of 50x. (b) At magnification of 500x.

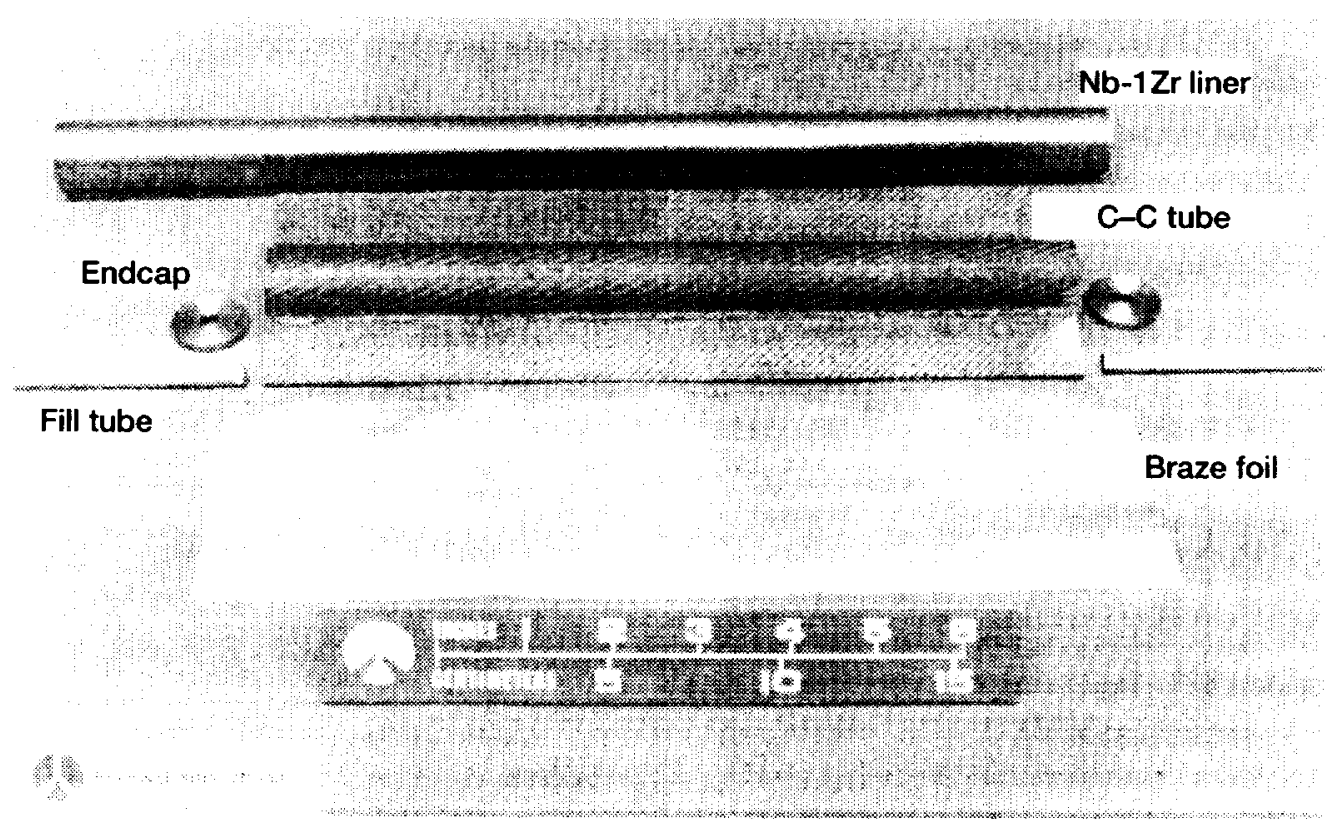

Figure 5.-Composite heat pipe elements prior to assembly.

In the filling operation, the minimization of impurities, especially oxygen, in the potassium working fluid is of utmost importance, because the resulting oxides have been shown to be the principal cause of heat pipe corrosion at operating temperatures (Lundberg, 1987). In 1986 a process for achieving very low oxygen concentrations in liquid-metal fluids (DeVan, 1986) was demonstrated at the Oak Ridge National Laboratory (ORNL). This liquid-metal flowthrough process with intermittent soak periods ensures that all wetted inner surfaces are free of adsorbed oxygen before the heat pipe is sealed. This procedure, with minor variations such as an initial vacuum bakeout period, was selected as the way to fill the heat pipe with potassium working fluid. Since refractory metals were being used at elevated temperatures, all filling operations were performed in a glovehox with an inert gas atmosphere. Prior measurements had shown that the equipment used was 

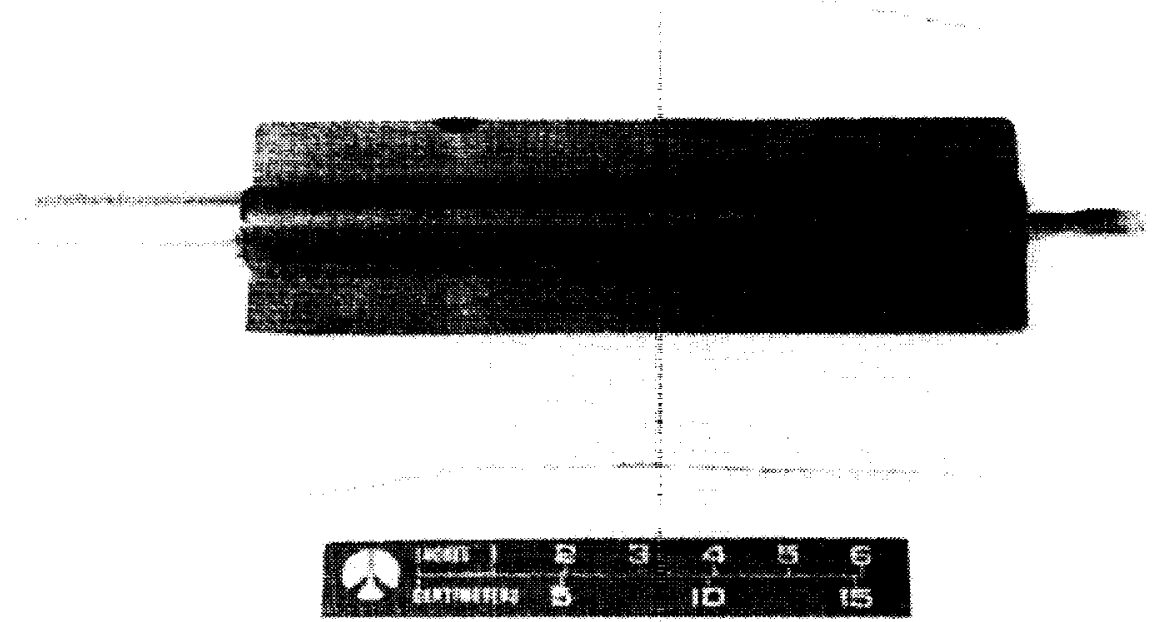

Figure 6.-Assembled and instrumented heat pipe test article.

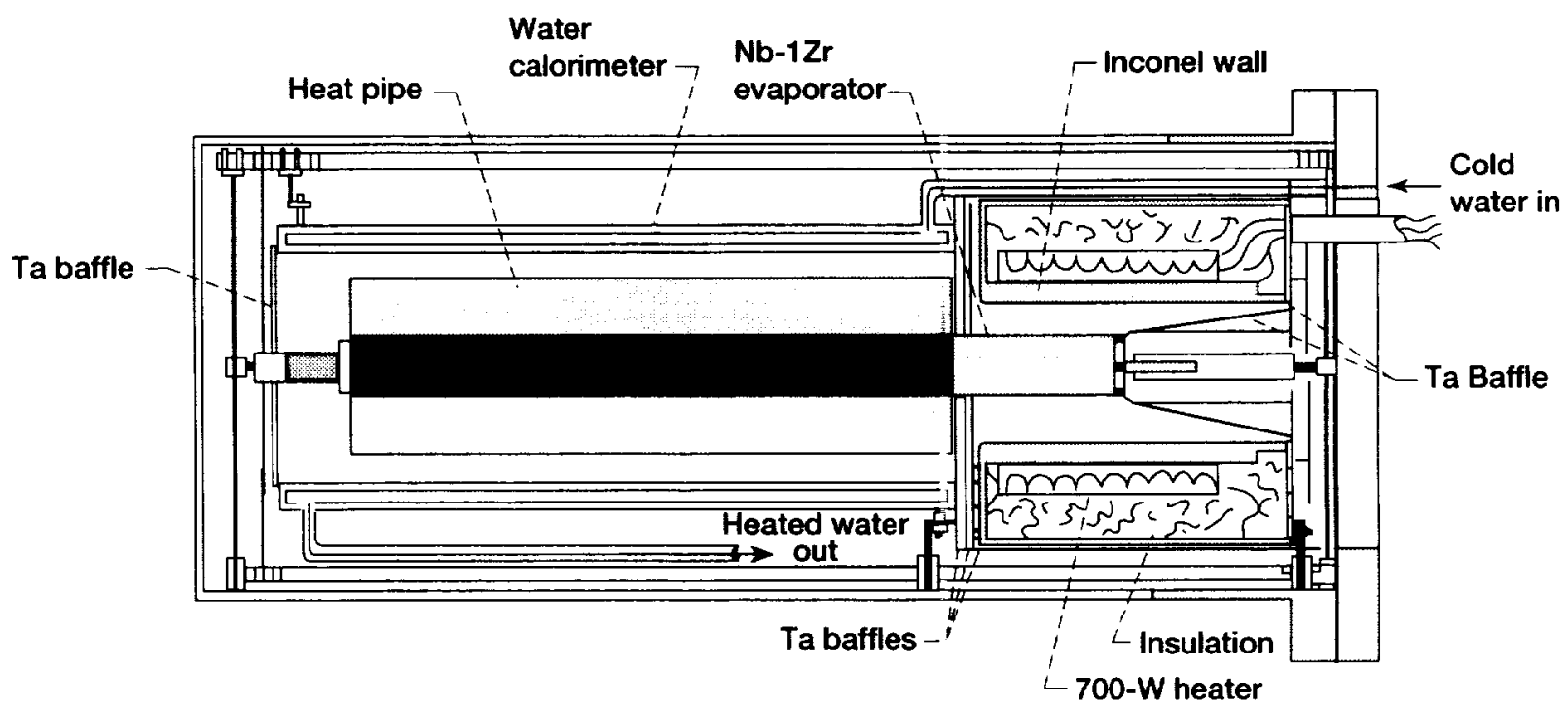

Figure 7.-Heat pipe installed in vacuum enc losure prior to testing.

capable of keeping oxygen and moisture concentrations below $1 \mathrm{ppm}$, and nitrogen concentrations below $5 \mathrm{ppm}$. After completion of the filling operations, the fill tubes were pinched and welded. Figure 6 shows the completed heat pipe and the thermocouple instrumentation.

\section{Heat Pipe Testing}

To determine thermal performance, the heat pipe was instrumented with sheathed thermocouples $250 \mu \mathrm{m}$ ( 10 mils) in diameter. as shown in figure 1 . Thermocouples $3,4,6,10$, and 
12 were intended to measure axial temperature distribution, whereas thermocouples 5 through 9 and 11 were intended to determine fin heat transfer and fin efficiency. Testing was carried out in a horizontal vacuum chamber equipped with a water calorimeter wall shroud, as shown in figure 7 . Thermocouples were also installed inside the calorimeter cooling water inlet and outlet tubes to measure water temperature rise during testing. A vacuum of $10^{-5}$ torr was maintained within the chamber during testing. The input heat was supplied to the evaporator section by a radiation-coupled electrical resistance heater. To prevent degradation of the heater elements, an Inconel enclosure was used to isolate the heaters from the vacuum. In addition, the inside surface of this cylindrical enclosure was surface-treated to raise its emissivity to a value above 0.9. To minimize heat losses to the vacuum chamber from the heaters, the heater elements were insulated with layers of ceramic fiber material. Multiple layers of highly reflective tantalum foil baffles were also installed to isolate the heaters from the condenser section, end flanges, and supports.

\section{Test Results}

As indicated in figure 8, the heat pipe test was conducted over an 11.5-hr period, with the heat pipe initially at ambient temperature and the potassium working fluid in the solid state. To conduct the test without risking evaporator dryout, input power was added gradually in 20-10-30-W increments every 15 to $20 \mathrm{~min}$, starting with an initial heater temperature of $300 \mathrm{~K}$. Once temperatures in the first section of the condenser (thermocouples 3 to 5 ) rose above the melting point of the potassium working fluid $(336.7 \mathrm{~K})$, the rate of heat input was increased until the maximum heater limit of $770 \mathrm{~W}$ was reached near the end of the test period: at this point, the heater temperature was measured as $1270 \mathrm{~K}$. Because of the low thermal absorptivity of the $\mathrm{Nb}-1 \mathrm{Zr}$ evaporator surface $(\sim 0.4)$, only about $300 \mathrm{~W}$ of heater power was actually absorbed by the evaporator. Hence, future testing with radiant heat input would require that the evaporator surface absorptivity be raised by electric arc texturing (Mirtich and Kussmaul, 1987).

Cost and time constraints have prevented this step for the tests conducted to date. Note, however, that in the application intended by the original SP-100 power system design. the evaporator would be convectively heated by lithium fluid. and therefore, enhancement of evaporator surface absorptivity to radiation heat transfer would not be necessary.

Figure 9 shows the axial temperature profile development with time, after the start of evaporator heat input, as a parameter. Regrettably, since thermocouple 12 had become detached and failed early during the testing, data are available only for the first $19.6 \mathrm{~cm}$ of the condenser. As expected, the axial profile of the condenser surface temperature was flat initially, until the potassium melting point was exceeded and heat pipe operation was established in an increasingly longer portion of the

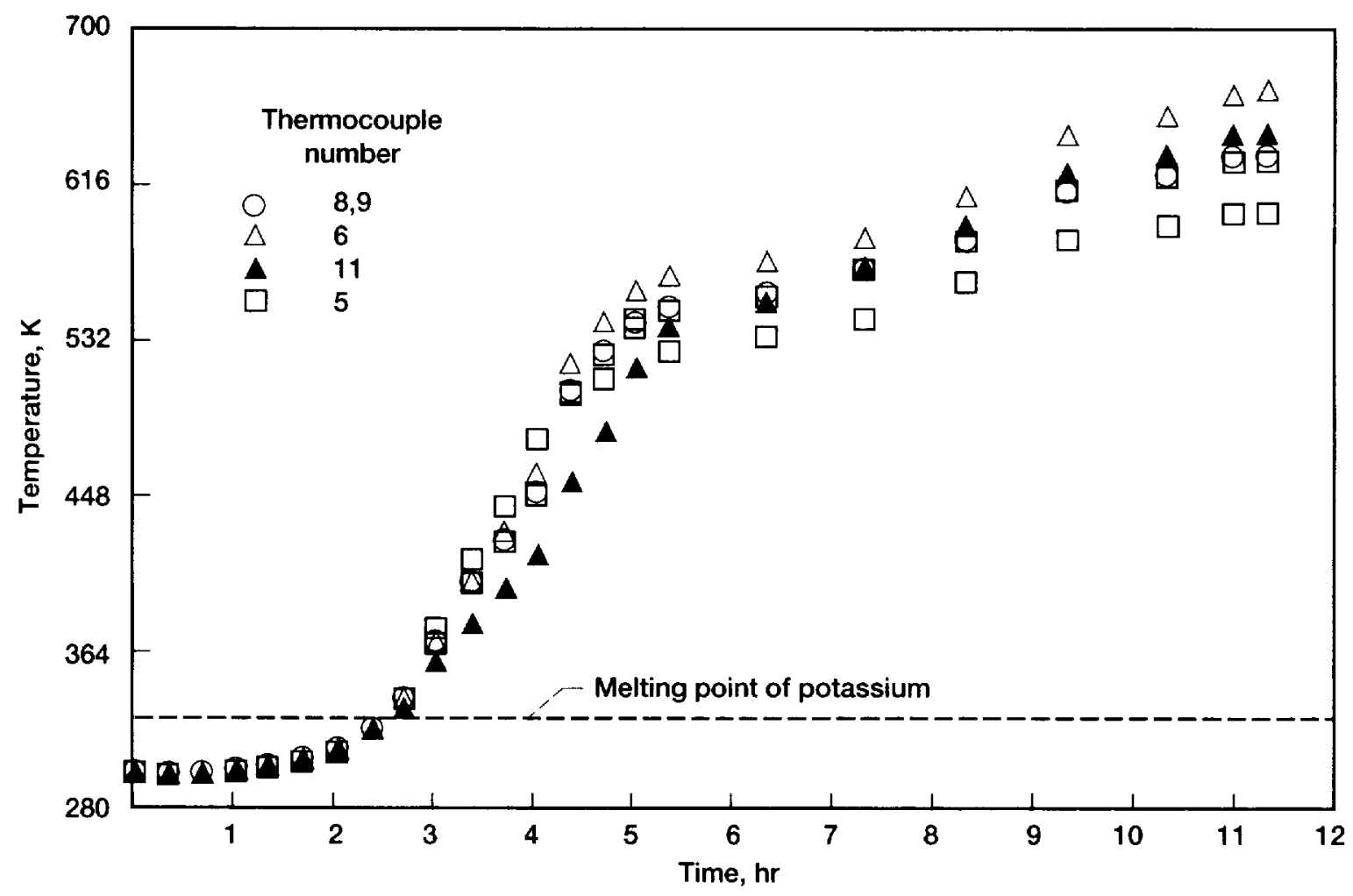

Figure 8. - Heat pipe local temperature readings during startup period. 




Figure 9.-Heat pipe axial temperature profile development.

condenser. Thus, by the third hour a distinct temperature gradient was produced between the 2.5 - and $8.2-\mathrm{cm}$ locations, indicating incipient potassium recirculation (i.e., refluxing) in the upstream section of the condenser. Refluxing extended to the $13.9-\mathrm{cm}$ location in the fourth hour, with thermocouples 5 and 8 at approximately the same temperature and thermocouple 11 (at the downstream location) showing a temperature approximately $50 \mathrm{~K}$ lower. This may indicate a sonic limit between the 13.9- and the 19.2-cm locations of the condenser. After $5 \mathrm{hr}$, internal recirculation of potassium appears to have become fully developed all the way out to the thermocouple 11 location. Moreover, the axial temperature profile has a slightly positive slope. which may be due to stagnation temperature recovery at the downstream end of the condenser.

Fin efficiency (defined as the actual heat radiated by the fin divided by the theoretically radiated heat if the entire fin were at the root temperature) was determined to be 80 percent on the basis of readings from thermocouples 6 through 9 . The fin temperature protile generated by these readings indicates that most of the thermal resistance is concentrated at the fin hase. This agrees with the finite difference code results for rectangular fins. as shown in appendix $A$. Fin geometries approximating a parabola not only would eliminate the high $\Delta T$ at the fin root (i.e.. fin base) but also would provide more structural rigidity at the base.

Post-test examination of the heat pipe and associated test hardware showed all items to be in excellent condition. No changes could be detected in the $\mathrm{C}-\mathrm{C}$ tube shell, braze joints, or liner. This shows that the overall design and the fabrication process were hasically sound, considering that the test article was subjected to eight thermal cycles during fabrication, filling, and testing. These cycles included brazing and degassing at over $920 \mathrm{~K}$, three potassium filling cycles ranging from 425 to $875 \mathrm{~K}$, installing thermocouples at $575 \mathrm{~K}$, checkout testing at $525 \mathrm{~K}$, and performance testing at nearly $700 \mathrm{~K}$. The ternary alloy braze bond between the $\mathrm{C}-\mathrm{C}$ shell and liner, and the liner itself, both maintained their structural integrity throughout the thermal cvcles and ambient temperature storage. On the basis of these iesults, the heatup rate during future testing and in actual ser vice could be increased significantly.

It shou $\mathrm{d}$ be pointed out that a limited amount of testing was also acco:nplished with a second heat pipe in the $40010450 \mathrm{~K}$ temperatt re range by using a stainless steel liner, with demineralized water serving as the heat pipe working fluid. A significant result from this test was that the liner remained intact (no leaks developed) at water vapor pressures of 16 bar.

\section{Segmented Radiator Design}

The $\mathrm{C}-\mathrm{C}$ heat pipe fabricated and tested as described herein can be co usidered a potential element of a large multisegment space radiator. The literature on space radiator survivability (English and Guentert, 1961) indicates that if a space radiator is compo ed of a multiplicity of independently operating segments. a r indom micrometeoroid puncture of the radiator would result in the loss of only the punctured segment-not the entire radiator. Hence, the strategic advantage of segmented radiators for space service applications is obvious. The tradeoff between the number of segments and the segment wall thickness, in 
order to achieve minimum radiator weight, can be derived on the basis of a simple probability analysis:

If we assume that for each of $N$ identical radiator segments the probability of not being punctured is $p$, then the probability $S$ of having at least $N_{s}$ segments not punctured during the spacecraft radiator's design life is given by the cumulative binomial distribution as

$$
S=\sum_{n=N s}^{n=N} \frac{N !}{n !(N-n !)}(1-p)^{N-n} p^{n}
$$

For each segment the probability $p$ of no puncture is given by

$$
p=e^{-h u t} \text {, or } \ln (1 / p)=h a t
$$

where $h$ is the average puncture rate per unit time and unit area; $a$ is the vulnerable area of each segment; and $t$ is the required useful life of the radiator.

The puncture rate $h$ is a function of both the depth of penetration and the rate of flux of meteoroids. Furthermore, Summers and Charters (1959) have shown that the wall thickness $T_{w}$ which a meteoroid will barely penetrate is proportional to the cube root of the meteoroid mass, and the meteoroid flux (number frequency) is inversely proportional to meteoroid size (i.e., meteoroid mass). Assuming that the meteoroid velocity is essentially independent of mass, we can express these trends as a simple relationship:

$$
h \sim m^{-1} \sim T_{w}^{-3}
$$

With the objective of minimizing the initial weight of the vulnerable radiator surface material while ensuring a specified nonpunctured area at the end of radiator design life, we can write the following expression:

$$
W / N_{s} a=\rho T_{w} N / N_{s}
$$

where $W$ is the initial weight, $\rho$ is the density of the radiator surface material, and $N_{s} a$ is the required final area. In minimizing $W / N_{s} a$, for simplicity, only the weight of the vulnerable surface area is considered; the fin area, manifolding, and structure are not taken into account. Since material density $\rho$ may he assumed to be aconstant for a given radiator, it becomes an invariant in the analysis. A relative weight $w$ can then be defined as

$$
w=\left(N / N_{s}\right)\left[N_{s} \ln (1 / p)\right]^{-1 / 3}
$$

Then the total weight $W$ can be approximated as

$$
W \sim\left(N_{s} a\right) w\left(N_{s} a t\right)^{1 / 3}
$$

Since the required radiator area at the end of the mission and the required mission life are input parameters for the analysis and thus are known a priori. the product $N_{s} \cdot a \cdot t$ can be considered a constant. Segmenting influences the weight per unit area $\left(W / N_{s} a\right)$ required at the end of life by affecting the relative weight term $w$. Using equation (4) to solve for $T_{n}$ and arbitrarily defining the weight and wall thickness as unity for a nonsegmented radiator with a survival probability of 0.999 . we can compute and plot relative weight $u$ and wall thickness $T_{n}$ for a range of $N$ as a function of $N_{s} / N$, as shown in figure 10. Note the dramatic reduction in both weight and wall thickness that accrues because of radiator segmenting. The term $w$, that is, relative weight per unit segment area, decreases continually as the number of segments increases. English and Guentert showed that for large values of $N$ the minimum weight per unit segment area will occur at

$$
\left(N_{s} / N\right)_{\min }=e^{-1 / 4}=0.7788
$$

They obtained this minimization of $W / N_{s} \cdot a$ by holding the initial number of segments $N$ constant. For the work reported here, the author also performed the calculations for a constant number of surviving segments $N_{s}$. In this case, the value of $N_{s} / N$ for minimum weight per unit segment area will be

$$
\left(N_{s} / N\right)_{\min }=e^{-1 / 3}=0.7165
$$

Both approaches are valid and yield the same results. For design guidelines, the value of $N_{5} / N$ for minimum weight per unit segment area can be assumed to be

$$
\left(N_{s} / N\right)_{\min } \sim 0.75
$$

For a given number of segments $N$, the relative weight will increase for values of $N_{s} / N$ below the value given in equation (9) since as $N_{s}$ decreases, the vulnerable area of each segment increases and $p$, the probability of no puncture per segment, decreases.

As already mentioned in connection with the derivation of equation (4), fin area, radiator fluid manifolds, and structural weight were not included in this analysis. Regarding fin area. the following observation can be made: If a certain fraction of the vulnerable area $a$ of each segment represents the fin area not rendered useless, even if penetrated by a micrometeoroid. then the results of the present analysis will be conservative (i.e.. the relative weights and wall thicknesses will be even lower than shown in fig. 10). However, since the structure and manifolds will need to be protected by a thicker wall or a bumper shield, the benefits provided by fins will be offset to some degree, depending on the particular design of the spacecraft radiator. 


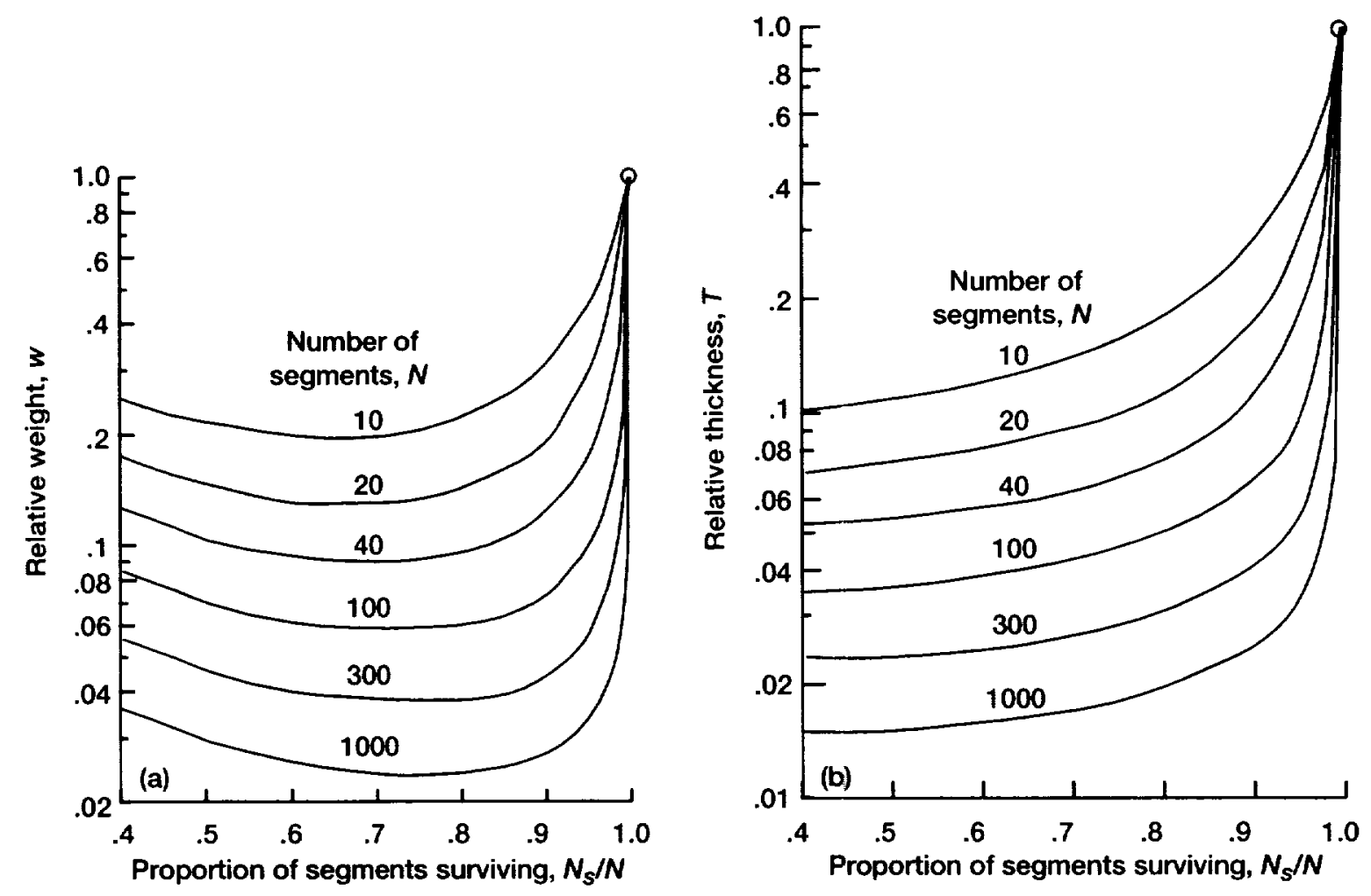

Figure 10.-Segmented heat pipe radiator characteristics for survival probability $S=0.999$. (a) Relative weight of vulnerable surface (nonsegmented $=1$ ). $(b)$ Relative wall thickness (nonsegmented $=1$ ).

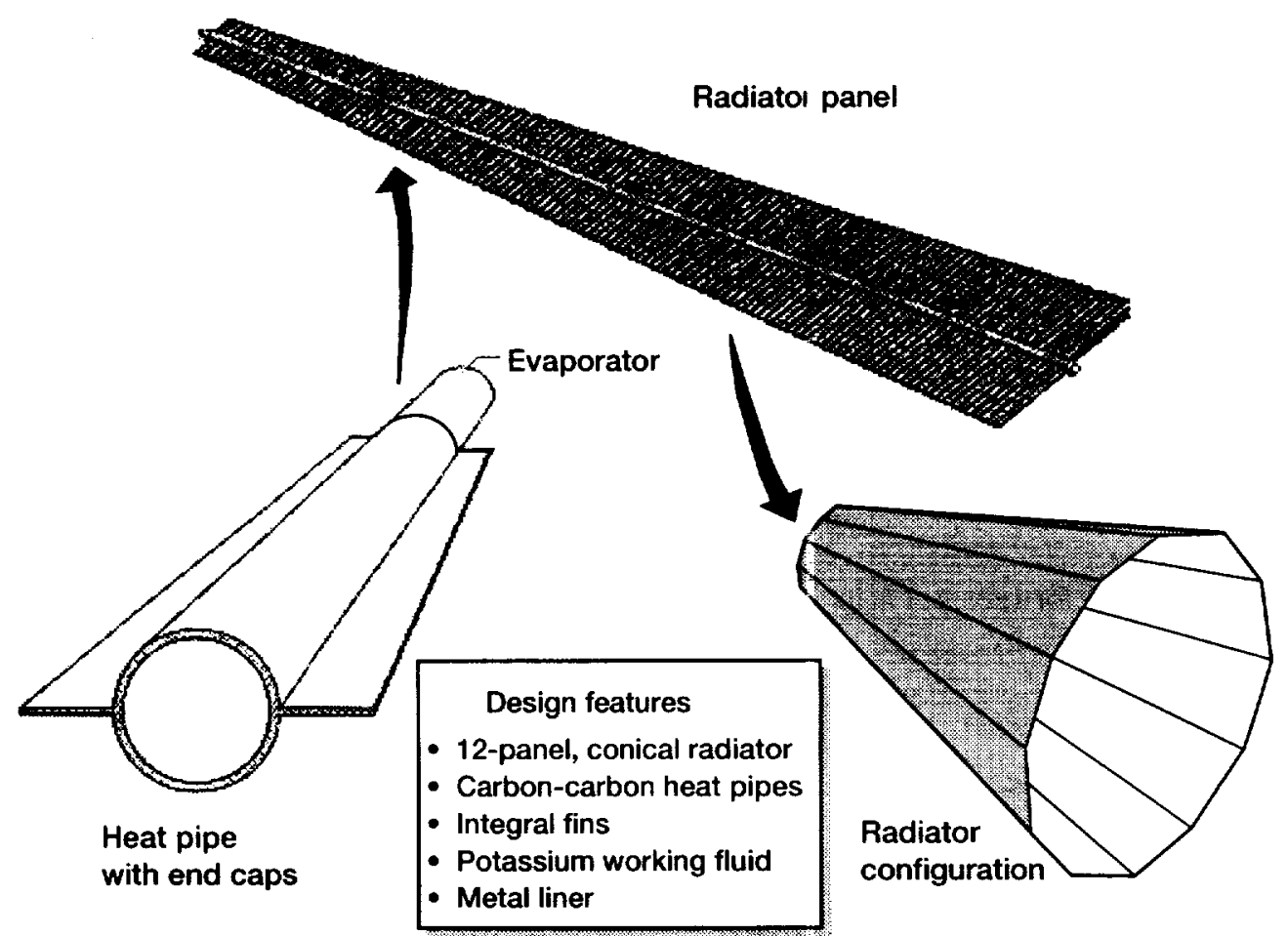

Figure 11. - SP-100 advanced heat pipe segmented radiator. 
Inset: Edge view of double $\mathrm{C}-\mathrm{C}$ face sheet configuration

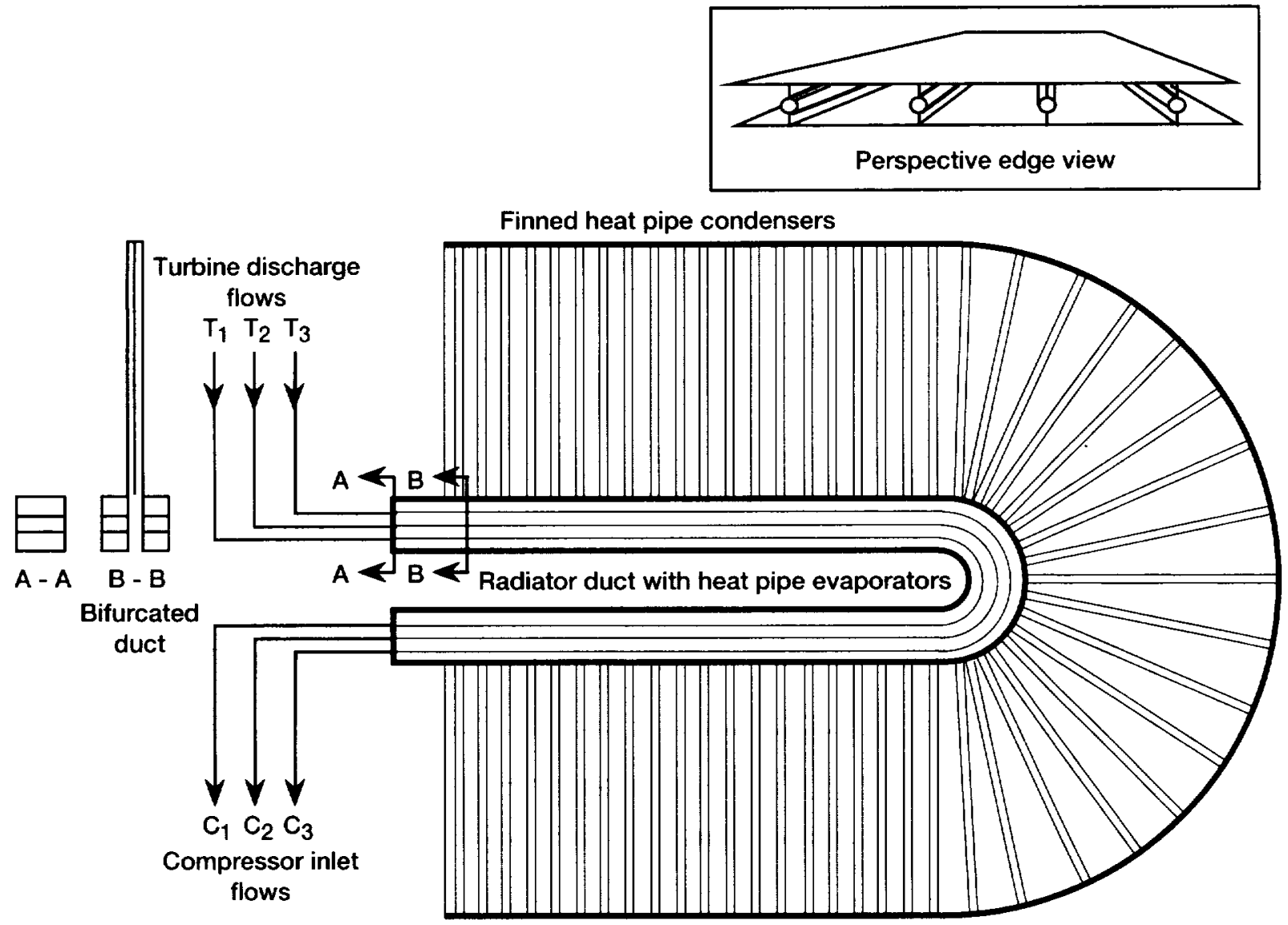

Figure 12.-Flat segmented heat pipe radiator for a nuclear triple loop gas turbine power system.

Nevertheless, the utilization of finned segments that increase the radiating area without increasing the vulnerable area will provide an additional margin in the design of large segmented space radiators. The use of heat pipes, each operating independently with self-contained heat transport loops, will further facilitate the space radiator design process.

\section{Segmented Radiator Design Examples}

Having discussed some of the theoretical basis for segmenting radiators and for utilizing heat pipes as ideal elements or building blocks, let us next discuss a few advanced space radiator designs. The conical radiator for the $0.1 \mathrm{MW}_{\mathrm{e}} \mathrm{SP}-100$ thermoelectric space power system with a liquid-metal (lithium) cooled reactor heat source is shown in figure 11 . The radiator cone is composed of 12 panels, each of which is a radiator segment consisting of $226 \mathrm{C}-\mathrm{C}$ heat pipes of varying condenser length. These heat pipes are essentially of the same design as discussed in this report. The SP-100 radiator. designed for 7-yr survival probability of 0.99 , could provide the $2.4 \mathrm{MW}_{\mathrm{t}}$ heat rejection needs of the power system with only 11 of its 12 panels functioning, each with 75 percent of their original number of heat pipes.

Figure 12 shows a proposed heat rejection subsystem for a $15-\mathrm{MW}_{\mathrm{e}}$ closed-cycle gas turbine power system with a nuclear high-temperature gas reactor heat source (Juhasz et al., 1992). This segmented radiator system, which is composed of a large number of finned heat pipe segments, was designed to meet the heat rejection requirements of three separate gas turbine loops. A bifurcated manifold duct, which carries the He turbine exhaust stream, communicates thermally with $0.05-\mathrm{m}$ diameter, $1.5-\mathrm{m}$ long $\mathrm{C}-\mathrm{C}$ heat pipe evaporators by combined conduction-convection heat transfer. 


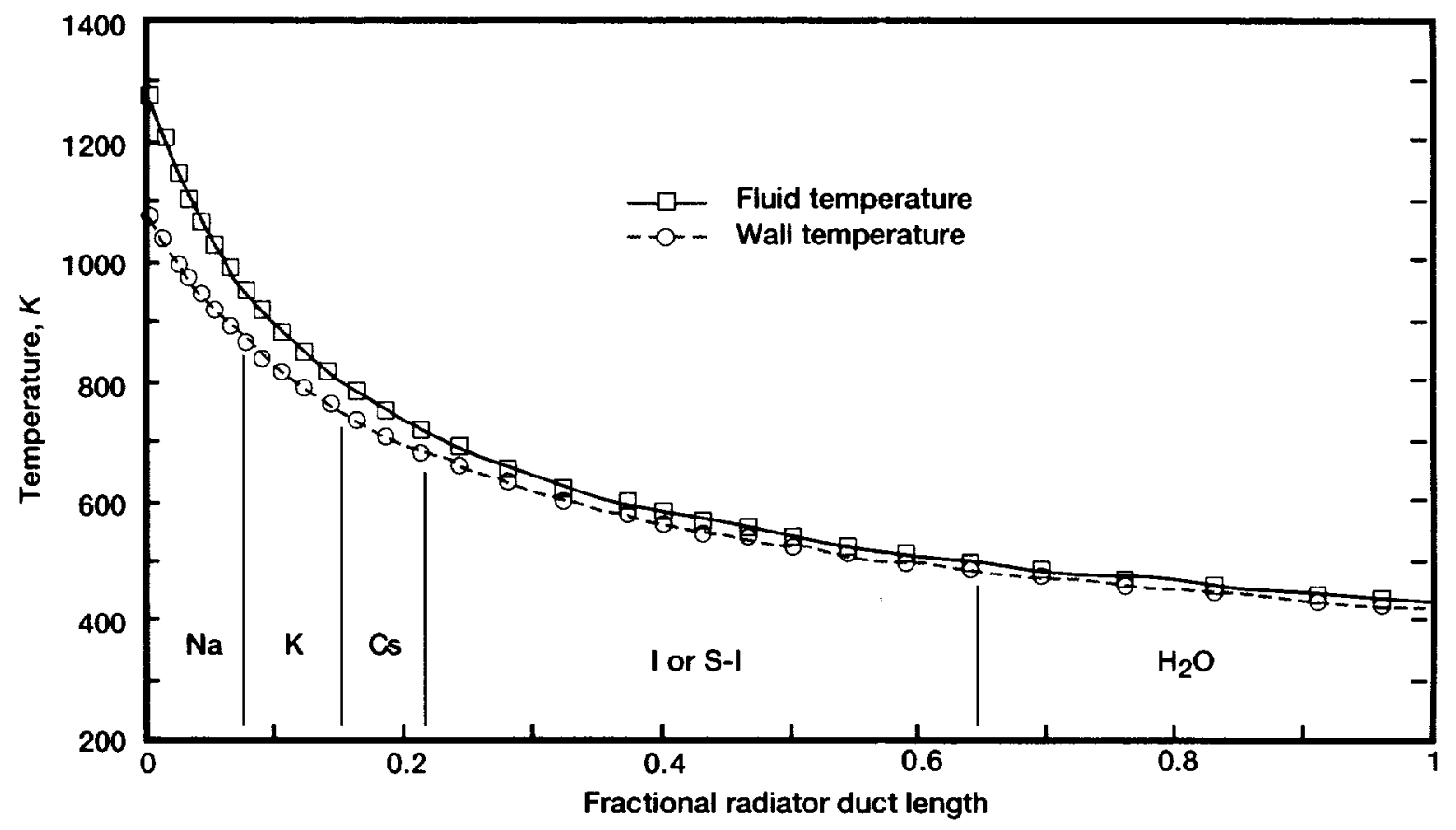

Figure 13.-Heat pipe radiator temperature profiles for a gas turbine power system. (Letters between lines designate heat pipe working fluids.)

The computed temperature profiles for the He gas and the heat pipe evaporator wall along the radiator duct are shown in figure 13. These profiles were computed under the assumption of constant incremental radiator area with incremental manifold duct length. To accommodate the more than $800-\mathrm{K}$ radiator temperature drop for this high-temperature gas turbine power system (turbine inlet temperature of $2000 \mathrm{~K}$ ), the radiator was divided into five temperature zones, each of which is defined by the operating temperature range associated with a particular heat pipe working fluid: sodium, potassium. cesium, sulfur-iodine (in lieu of mercury), and water. Note that the double $\mathrm{C}-\mathrm{C}$ face sheet configuration suggested by the perspective edge view offers even greater survivability and structural rigidity at a somewhat higher weight, depending on the thickness of the face sheets. As is evident from figure 13 , the design of a heat rejection radiator for a closed cycle gas turbine space power system will be a definite challenge to heat pipe manufacturing technology.

A section of a megawatt-level lunar-base nuclear reactor power system (Juhasz and Bloomfield, 1994) is shown in figure 14 This conceptual design could also be used for any planetary surface power plant, as long as the planet or planetary satellite $\mathrm{r}$ ad a solid surface (e.g., Mars or Titan). The radiator would be composed of eight vertical flat radiator panels, each serving a parallel redundant gas turbine power unit. To reduce reradiaticn from the lunar surface, a reflective aluminized Mylar blanket could be used to cover a sufficiently large area adjacent to the radiator, as indicated in figure 14 (a). Efficient utilizatio: 1 of indigenous materials, such as excavated planetary soi for reactor shielding and vertical radiator panel erection, is shown in the cutaway view of figure 14 . 

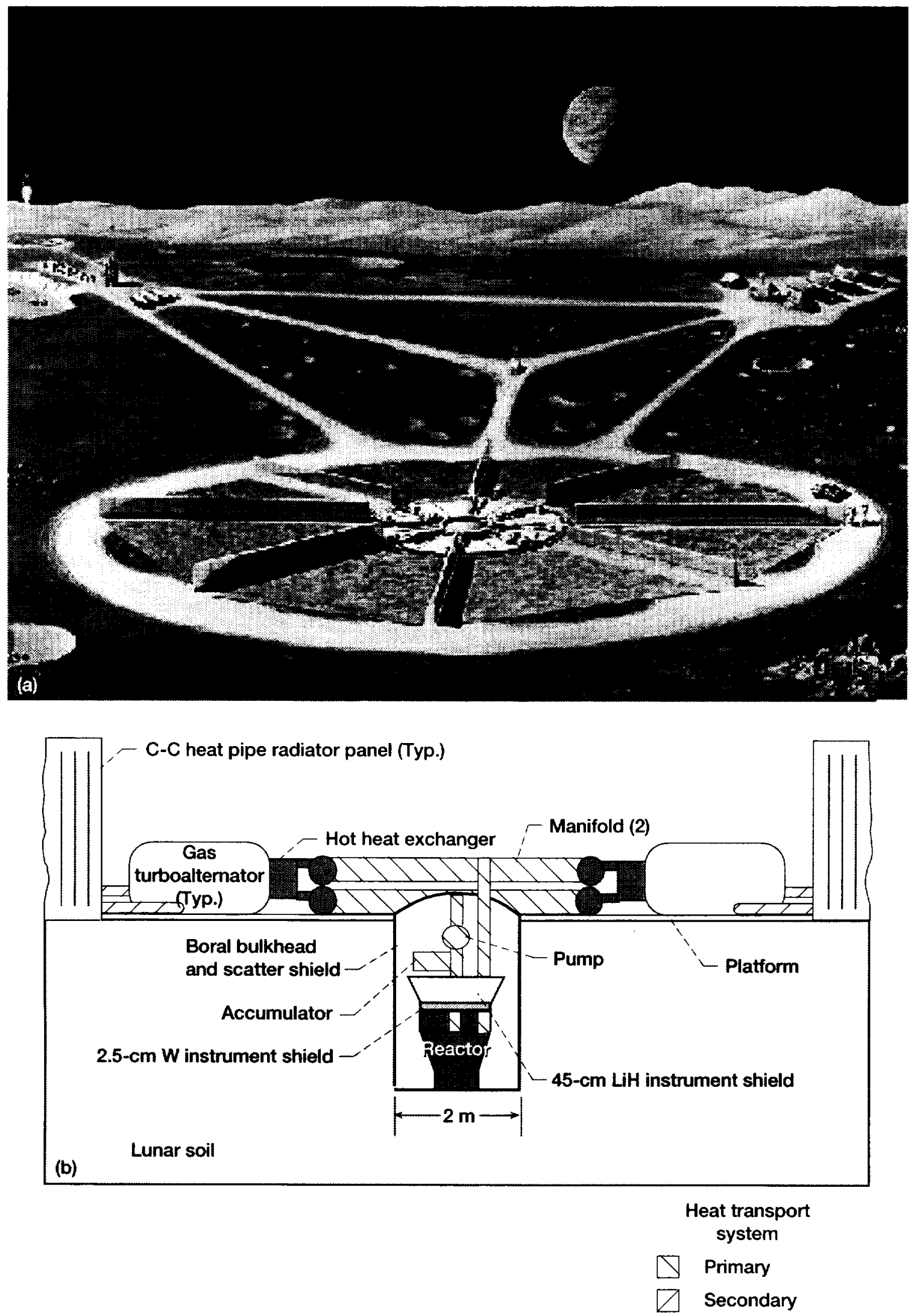

Figure 14.-Integrated nuclear power system for megawatt level lunar power plant. (a) Artist's rendering. (b) Cutaway view of installation on and below lunar surface. 


\section{Concluding Remarks}

A lightweight $\mathrm{C}-\mathrm{C}$ prototype liquid-metal heat pipe for space applications has been designed, fabricated, and successfully tested. The actual specific mass of the heat pipe with integrally woven $\mathrm{C}-\mathrm{C}$ fins was under $1.5 \mathrm{~kg} / \mathrm{m}^{2}$ for two-sided heat radiation that would occur with flat plate radiator configurations. For heat rejection applications in which only one side of the radiator was exposed to the space sink, the specific mass was under $3 \mathrm{~kg} / \mathrm{m}^{2}$. These specific mass values are less than one-third of the values commonly found in current space radiators. It was also shown that the very high conductivity $\mathrm{C}-\mathrm{C}$ materials currently being developed may lead to radiator specific mass values approaching $1.0 \mathrm{~kg} / \mathrm{m}^{2}$.

Although the heat pipe tested was designed to operate in the 700 to $850 \mathrm{~K}$ temperature range with its potassium working fluid, the technology can be extended to cover a broad range of temperatures by properly selecting alternate heat pipe working fluids and compatible liner material. As indicated in the text, the technology was also demonstrated for the 400 to $450 \mathrm{~K}$ temperature range, albeit without extensive instrumentation and data collection, by using a stainless steel liner and water as the working fluid. The advantage of using the lightweight $\mathrm{C}-\mathrm{C}$ heat pipes in the design of segmented space radiators was also demonstrated from two points of view: survivability in a micrometeoroid space environment; and (2) efficient radiation heat transfer by utilizing the high thermal conductivity of $\mathrm{C}-\mathrm{C}$ material in a finned condenser configuration

Since the treatment of and solution to the problem of heat radiation from a fin has not yet been found in the pertinent literature, a one-dimensional analysis and a brief discussion of a numerical finite difference solution technique developed by the author has been included in appendix $A$.

National Aeronautics and Space Administration Lewis Research Center

Cleveland, Ohio 44135, September, 1998 


\section{Appendix A}

\section{Analysis of Heat Transfer from a Radiating Fin}

In performing this analysis, consider the one-dimensional conduction and radiation heat transfer processes, as depicted in figure 15 , and the accompanying nomenclature showing the variables that are essential to the derivation of the characteristic ordinary differential equation governing the heat transfer. Note that the longitudinal dimension in the direction of heat flow (i.e., the fin root-to-tip dimension) has been designated $\mathrm{L}$, with the variable dimension being designated $\mathrm{x}$, where $0<\mathrm{x}<\mathrm{L}$. This nomenclature is not consistent with that used in table 1 (root-to-tip dimension referred to as W), but it is consistent with those used in this appendix.

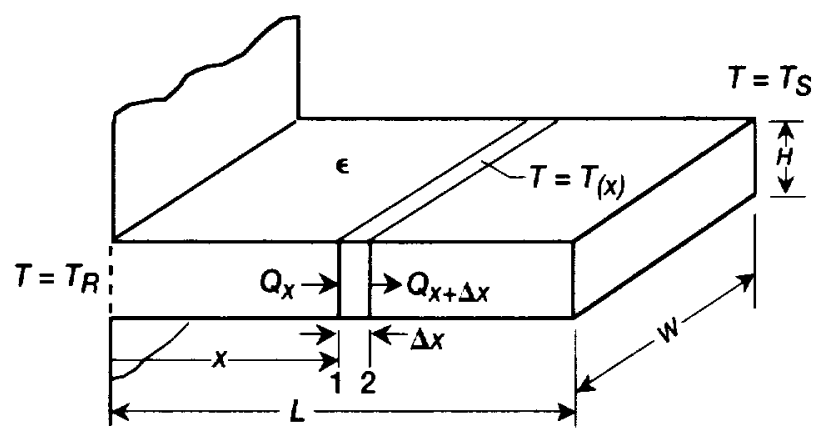

Figure 15.-Sketch showing nomenclature for radiating fin heat transfer analysis.

TABLE II_-APPENDIX A NOMENCLATURE

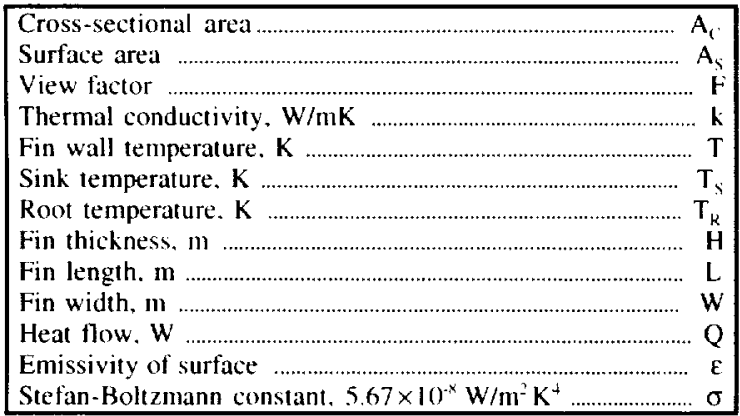



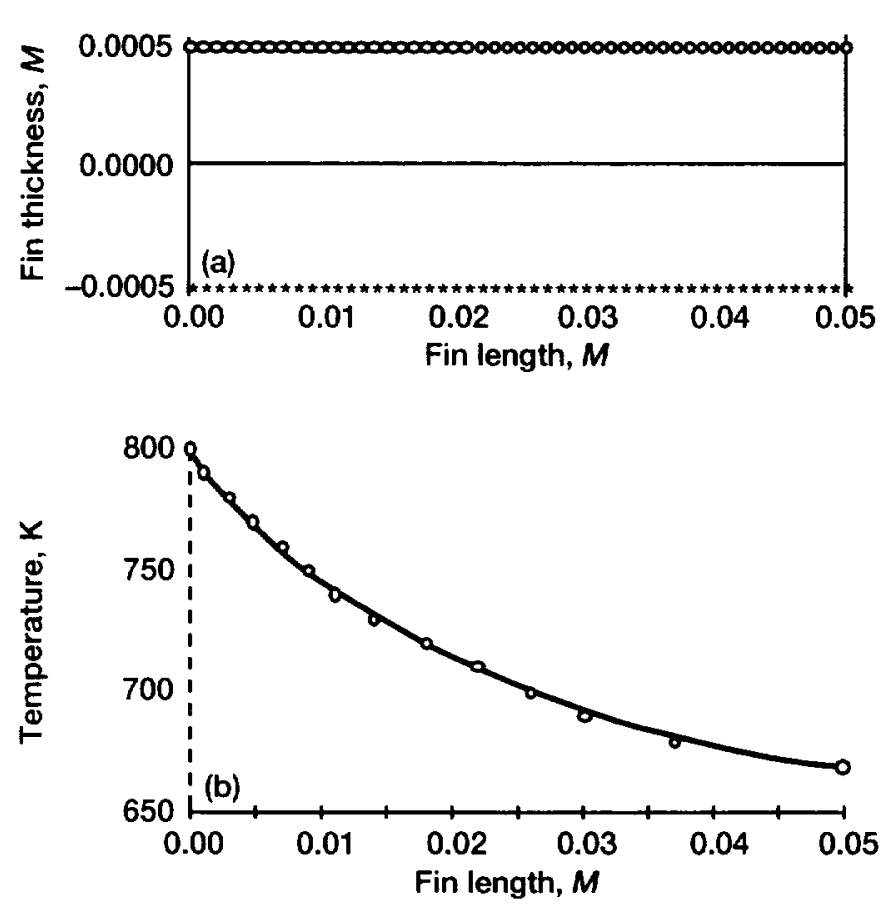

Figure 16.-Rectangular fin radiation heat transfer example. (a) Fin geometry profile. (b) Fin temperature profile (for $k=200 ; \epsilon=.85, F=1 ; T_{S}=230 \mathrm{~K}$.
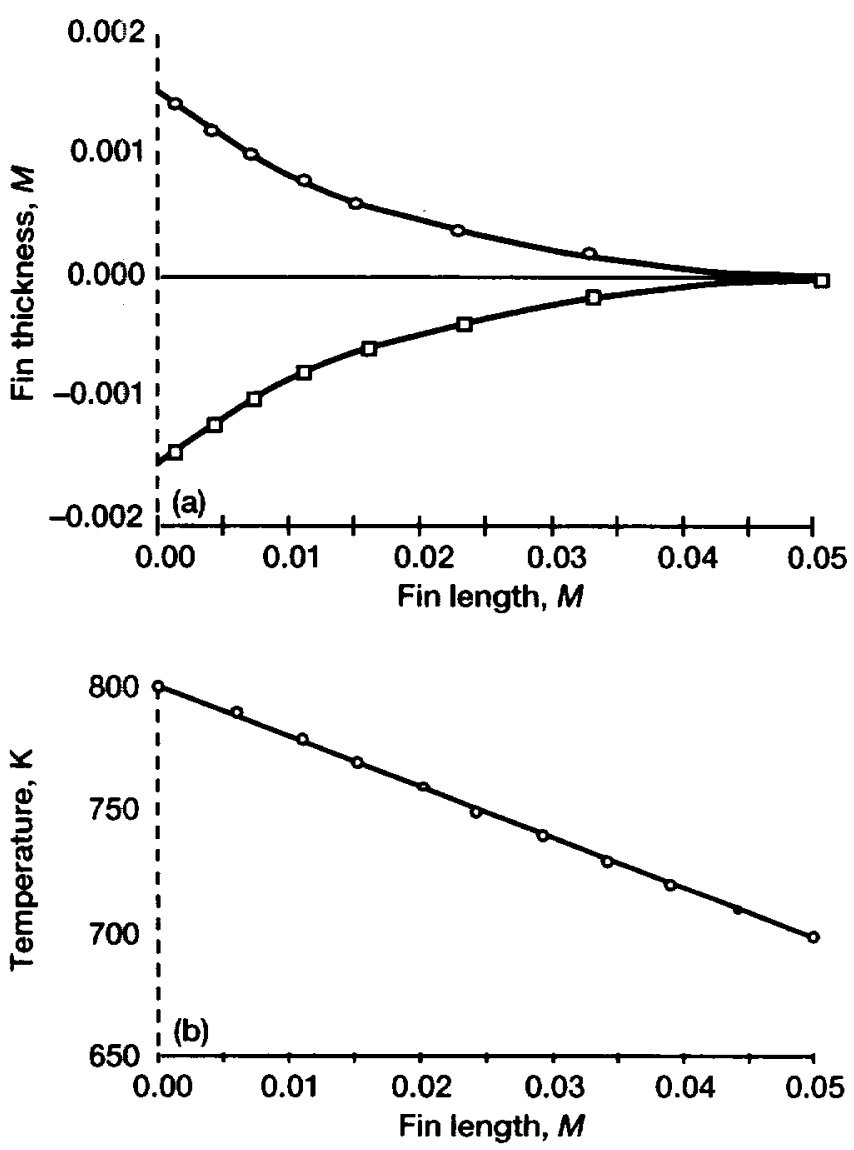

Figure 17.-Parabolic fin radiation heat transfer example. (a) Fir geometry profile. (b) Fin temperature profile (for $k=50 ; \epsilon=.85, F=1 ; T_{S}=230 \mathrm{~K}$ ).

from the fin surface, the temperature gradient decreases with fin length for a rectangular fin geometry, but is constant for the parabolic fin, resulting in a linear temperature profile. This is consistert for convectively cooled fins for which closed-form solution: do exist. Future work in this area will focus on combine 1 radiation and convection. 


\section{Appendix B}

\section{Symbols}

A area, $\mathrm{m}^{2}$

$A_{c} \quad$ cross-sectional area, $\mathrm{m}^{2}$

$A_{s} \quad$ surface area, $\mathrm{m}^{2}$

a radiator segment vulnerable area

$A O$ atomic oxygen

$F \quad$ view factor

$H \quad$ fin thickness, $\mathrm{m}$

$h \quad$ average puncture rate per unit time and unit area

$k$ thermal conductivity, $\mathrm{W} / \mathrm{mK}$

$L \quad$ fin length, $m$

$\mathrm{MW}_{\mathrm{e}}$ megawatts electric

$M W_{1}$ megawatts thermal

$m \quad$ micrometeoroid mass. $\mathrm{kg}$

$N \quad$ number of initial identical radiator segments

$N_{s} \quad$ number of surviving radiator $n \quad$ running summation index (eq. (1))

$p \quad$ probability of not being punctured during required life time

$Q \quad$ heat flow, W

$S \quad$ cumulative probability of at least $\mathrm{N}_{\mathrm{s}}$ radiator segments not being punctured

$T \quad$ fin wall temperature, $\mathrm{K}$

$T_{s} \quad$ sink temperature, $\mathrm{K}$

$T_{R} \quad$ root temperature, $\mathrm{K}$

$T_{n} \quad$ wall thickness, $\mathrm{m}$

$t \quad$ required useful radiator lifetime (yrs)

W total initial radiator weight, $\mathrm{kg}$; fin width in fig. 15

$w \quad$ relative radiator weight (mass) as compared to weight of unsegmented radiator

$\varepsilon \quad$ emissivity of radiating surface

$\rho \quad$ density of radiator surface material, $\mathrm{kg} / \mathrm{m}^{3}$

$\sigma \quad$ Stefan-Boltzmann constant $\left(5.67 \times 10^{-8} \mathrm{~W} / \mathrm{m}^{2} \mathrm{~K}^{4}\right)$ 


\section{References}

Brandhorst. H.W.. Jr.: Juhasz. A.J.: and Jones, B.I. (1991): Alternative Power Generation Concepts for Space. NASA TM-88876.

DeVan. J.H. (1986): Purification Procedure for Sodium Working Fluid in a Stainless Steel Heat Pipe. ORNL Letter No. 0828/05/86.

English. R.E.; and Guentert. D.C.(1961): Segmenting Radiators for Meteoroid Protection. Ars J., Aug. 1961, pp. 1162-1164.

Groll. M. (1973): Waermerohre als Bauelemente in der Waerme-und Kaeltetechnik. Brennstoff-Waerme-Kraft. vol. 25, no.1, pp. 11-14.

Juhasz. A.J.: and Jones, B.I. (1987): Analysis of Closed Cycle Megawatt Class Space Power Systems With Nuclear Heat Sources. Proceedings of the Third Symposium on Space Nuclear Power Systems. M.S. El-Genk. and M.D. Hoover. eds.. Ortit Book Co.. Malabar. FL.

Juhasz. A.J : El-Genk. M.S.: and Harper. W.B. Jr. (199.3): Closed Brayton Cycle Power System With a High Temperature Pellet Bed Reactor Heat Source for Nuclear-Electric Propulsion (NEP) Applications. NASA TM-105933.

Juhasz. A.J.: and Bloomfield. H.S. (1994): Development of Lightweight Radiators for Lunar Based Power Systerns. NASA TM-106604.
Juhasz, A.J.: and Peterson. G.P. (1994): Review of Advanced Radiator Technologies for Spacecraft Power Systems and Space Thermal Control. NASA TP-4555.

Juhasz, A I.: and Rovang. R.D. (1995): Composite Heat Pipe Development Status: Development of Lightweight Prototype Carbon-Carbon Heat Pipe W:th Integral Fins and Metal Foil Liner. NASA TM-106909.

Lundberg. L.B. (1987): Alkali Metal Heat Pipe Corrosion Phenomena. Sixth International Heat Pipe Conference. May 1987. Grenoble, France.

Mirtich, M.J.: and Kussmaul. M.T. (1987): Enhanced Thermal Emittance of Space Radiators by lon-Discharge Chamber Texturing. NASA TM-100137.

Montesano. M.J. (1996): New Material for Thermal Management Has Four Times Thermal Conductivity of Copper. Mater. Tech.. vol. 11. no. 3, pp. 87-91.

Rutledge. S.K.: Hotes, D.L.: and Paulsen, P.E. (1990): The Effects of Alomic Oxygen on the Thermal Emittance of High Temperature Radiator Surfaces. NASA TM-103224.

Summers, J.L. (1959): Investigations of High Speed Impact: Regions of Impact and Impact at Oblique Angles. NASA TN D-94 




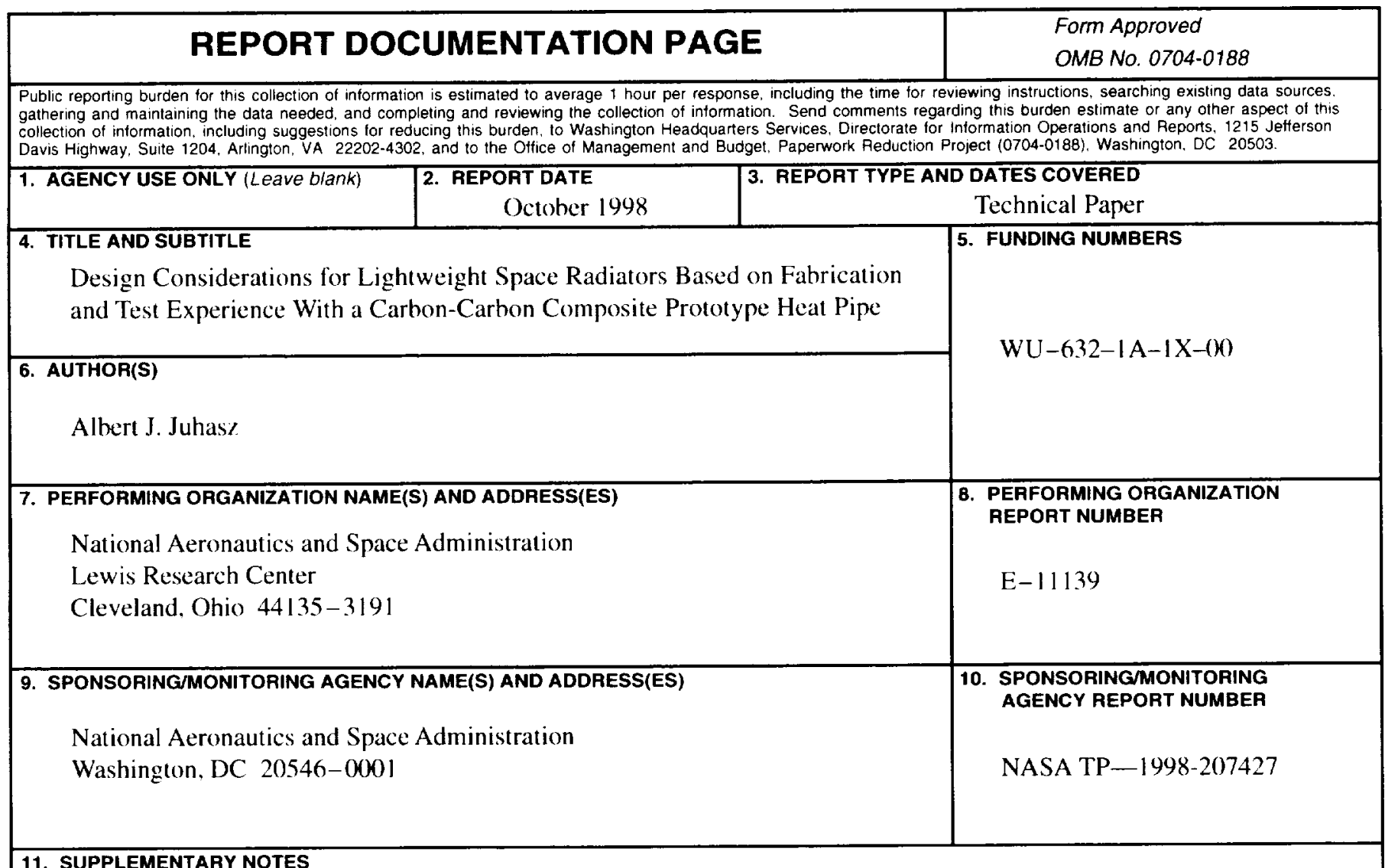

\section{SUPPLEMENTARY NOTES}

A portion of this material was presented at the 10th International Heat Pipe Conference held in Stuttgart, Germany, September 22-25, 1997. Responsible person, Albert J. Juhasz, organization code 5440, (216) 433-61.34.

12a. DISTRIBUTION/AVAILABILITY STATEMENT

12b. DISTRIBUTION CODE

Unclassified - Unlimited

Subject Categories: 24, 34, and 20
Distribution: Standard

This publication is available from the NASA Center for AeroSpace Information. (301) 621-0390.

\section{ABSTRACT (Maximum 200 words)}

This report discusses the design implications for spacecraft radiators made possible by the successful fabrication and proof-of-concept testing of a graphite-fiber-carbon-matrix composite (i.e., carbon-carbon (C-C)) heat pipe. The prototype heat pipe, or space radiator element, consists of a $\mathrm{C}$ - C composite shell with integrally woven fins. It has a thinwalled furnace-brazed metallic $(\mathrm{Nb}-1 \% \mathrm{Zr}$ ) liner with end caps for containment of the potassium working fluid. A short extension of this liner, at increased wall thickness beyond the $\mathrm{C}-\mathrm{C}$ shell, forms the heat pipe evaporator section which is in thermal contact with the radiator fluid that needs to be cooled. From geometric and thermal transport properties of the $\mathrm{C}-\mathrm{C}$ composite heat pipe tested, a specific radiator mass of $1.45 \mathrm{~kg} / \mathrm{m}^{2}$ can be derived. This is less than one-fourth the specific mass of present day satellite radiators. The report also discusses the advantage of segmented space radiator designs utilizing heat pipe elements, or segments, in their survivability to micrometeoroid damage. This survivability is further raised by the use of condenser sections with attached fins, which also improve the radiation heat transfer rate. Since the problem of heat radiation from a fin does not lend itself to a closed analytical solution, a derivation of the governing differential equation and boundary conditions is given in appendix A, along with solutions for rectangular and parabolic fin profile geometries obtained by use of a finite difference computer code written by the author.

\section{SUBJECT TERMS}

Space radiators; Heat pipes: Graphite-carbon composites

\begin{tabular}{|c|c|}
\hline $\begin{array}{c}\text { 17. SECURITY CLASSIFICATION } \\
\text { OF REPORT } \\
\text { Unclassified }\end{array}$ & $\begin{array}{c}\text { 18. SECURITY CLASSIFICATION } \\
\text { OF THIS PAGE } \\
\text { Unclassified }\end{array}$ \\
\hline
\end{tabular}

NSN 7540-01-280-5500

\begin{tabular}{|l|l|}
\hline \multirow{2}{*}{$\begin{array}{c}\text { 19. SECURITY CLASSIFICATION } \\
\text { OF ABSTRACT } \\
\text { Unclassified }\end{array}$} & $\begin{array}{c}\text { 15. NUMBER OF PAGES } \\
24\end{array}$ \\
\cline { 2 - 2 } & $\begin{array}{c}\text { 16. PRICE CODE } \\
\text { A03 }\end{array}$ \\
\hline
\end{tabular}


